\title{
Empathy, compassion fatigue and burnout in police officers working with rape victims
}

David Turgoose, Naomi Glover, Chris Barker, and Lucy Maddox

Version date: 8 February 2017

Manuscript accepted for publication in Traumatology

(C) 2017, American Psychological Association. This paper is not the copy of record and may not exactly replicate the final, authoritative version of the article. Please do not copy or cite without authors permission. The final article will be available, upon publication, via its DOI: $10.1037 / \operatorname{trm} 0000118$

Address correspondence to Dr David Turgoose <d.turgoose@alumni.ucl.ac.uk> 


\begin{abstract}
Police officers who work with victims of rape and sexual assault are exposed to severely traumatic material. This study aimed to investigate whether these specialist officers had developed compassion fatigue, secondary traumatic stress and burnout, and whether these variables were associated with trait and situational empathy, an important factor in retaining victim involvement within the prosecution process. The study also piloted a brief training intervention aimed at educating officers about compassion fatigue and ways of reducing and preventing it.
\end{abstract}

A convenience sample of specialist police officers $(N=142)$ who work with victims of sexual assault completed measures of compassion fatigue, secondary traumatic stress and burnout, as well as two empathy measures, rating trait empathy and 'in vivo' empathy in response to a video vignette. Cross-sectional analysis showed that longer-serving specialist officers had greater compassion fatigue, secondary traumatic stress and burnout, but that neither measure of empathy was related to compassion fatigue or secondary traumatic stress, although high burnout was related to low trait empathy. The training was well received, and pre and post-test measures showed that officers' knowledge of the constructs increased.

Given the potential risks to their well-being and work performance, officers would benefit from further support to cope with and prevent emotional distress. Higher empathy might protect against burnout. Longitudinal research is needed to better understand the relationships between empathy, compassion fatigue, secondary traumatic stress and burnout.

Key words: Compassion fatigue, Secondary traumatic stress, Burnout, Empathy, Police 


\section{Introduction}

Victims of rape and sexual assault are likely to develop signs of Post-Traumatic Stress Disorder (PTSD; Kilpatrick, Saunders, Veronen, Best \& Von, 1987; Pegram \& Abbey, 2016), shame and self-blame (La Bash \& Papa, 2014; Lee, Scragg \& Turner, 2001) following an assault. Professionals who work with such victims can be exposed to traumatic material and victims' distress, and may therefore be at risk of developing psychological difficulties themselves (Figley, 1995; Schauben \& Frasier, 1995). Some specialist police officers are trained to gather evidence in cases of rape and sexual assault. Part of this role involves taking detailed accounts from victims, a role that involves being exposed to potentially traumatic material.

Various terms have been used to describe the possible consequences of such exposure, including compassion fatigue (Figley, 2002), secondary traumatic stress (Figley, 1995), and burnout (Maslach, 1982; Elwood, Mott, Lohr \& Galovski, 2011).

The term compassion fatigue is often used interchangeably with secondary traumatic stress and was initially described as a type of secondary traumatic stress reaction (Figley, 1995). More recently, definitions of compassion fatigue have described the potential impact of working with traumatised individuals, such as a reduction in the capacity or interest in bearing the suffering of others (Figley, 2002), physical and emotional exhaustion and a pronounced reduction in the ability to feel empathy and compassion for others (Elwood et al., 2011; Evces, 2015; Mathieu, 2007).

Secondary traumatic stress describes the development of PTSD-like symptoms in individuals exposed to the trauma of another (Figley, 1995). Similarly to PTSD, signs of secondary traumatic stress relate to arousal, avoidance and intrusive thoughts or memories. As with compassion fatigue, difficulties can develop in individuals not from directly 
witnessing or experiencing a traumatic event, but by hearing about another person's trauma. Secondary traumatic stress is hypothesized to occur quickly and unexpectedly in reaction to exposure to the details of one or more traumatic events (Elwood et al., 2011; Figley, 1995).

Burnout has been described as psychological and emotional exhaustion, associated with feelings of hopelessness and difficulties in dealing with work or in doing one's job effectively (Stamm, 2010), and is not specific to those working with victims of trauma. It is also associated with a reduced sense of professional accomplishment (Maslach, 1982), cynicism and inefficacy resulting from long-term exposure to work-related stress (Maslach, Schaufeli, \& Leiter, 2001).

Compassion fatigue, secondary traumatic stress and burnout have been found to be prevalent in several healthcare and helping professions, e.g. emergency workers (Cicognani, Pietrantoni, Palestini \& Prati, 2009); physicians (Gleichgerrcht \& Decety, 2014); nurses (Hegney, Craigie, Hemsworth, Osseiran-Moisson, Aoun, Francis \& Drury, 2014); oncology social workers (Simon, Pryce, Roff \& Klemmack, 2005); chaplains (Yan \& Beder, 2013); and mental health practitioners (Zeidner, Hadar, Matthews \& Roberts, 2013). One population that has not yet been investigated is police officers, in particular those who work with victims of sexual assault; a traumatic crime with high incidences of victim PTSD (Kilpatrick et al., 1987).

In contrast to the challenges described above, the term compassion satisfaction has been used to describe the positive aspects of working in helping professions. It has been suggested that professionals and carers can gain pleasure and satisfaction from helping and making a difference to the lives of others (Figley \& Stamm, 1996).

\section{Compassion fatigue and empathy}


It has been proposed that compassion fatigue is associated with a reduction in empathy (e.g. Evces, 2015; Mathieu, 2007) although this has not yet been conclusively established. Figley (1995) suggested that professionals who have a high capacity for feeling and expressing empathy are more at risk of compassion fatigue. He proposed that empathy leads individuals to experience the emotional distress of those they are helping, and this contributes directly to the development of compassion fatigue as a secondary traumatic stress response (Figley, 2002). Figley's model suggests that highly empathic individuals are more likely to develop compassion fatigue. At the same time, one of the effects of compassion fatigue is a gradual reduction in empathy (Mathieu, 2007).

\section{Empathy and the police}

Empathy has long been established as playing an important role in psychological therapy, particularly in forming good therapeutic relationships (Bohart \& Greenberg, 1997; Rogers, 1975) and more recently has also been recognised across a range of other helping professions (e.g. López-Pérez, Ambrona, Gregory, Stocks \& Oceja, 2013; May, 2013). Empathy has also been shown to potentially be important in the police's work with victims of rape and sexual assault. Research suggests that victims' experiences of engaging with the police impact on attrition rates in rape cases. For example, the amount of empathy that victims perceive in their investigating police officer has been associated with the likelihood of them deciding to continue with the prosecution process and go to court (Maddox, Lee \& Barker, 2011). Victims who feel comfortable with their interviewing officer are also more likely to disclose more information (Greeson, Campbell \& Fehler-Cabral, 2015; Patterson, 2011). 
Attrition of rape cases in the legal system and low conviction rates has attracted widespread public interest in the UK. In particular, concern was raised about the fall in conviction rates in 2013-14, given that rates had gradually been increasing. In 2014, it was common to see headlines such as "Why are rape conviction rates falling?" (Channel 4 news, 2014), or "Measures aimed at addressing drop in rape convictions launched" (Casciani, 2014).

The UK Crown Prosecution Service (CPS) and police have recently shown commitment to address these issues (CPS, 2014). However, it remains important to investigate reasons why the conviction rate for rape remains low and factors that might relate to police officers' ability to display empathy towards victims. One possible contributory factor might be that the effects of compassion fatigue, secondary traumatic stress or burnout are making it harder for officers to feel and display empathy, which may in turn be affecting victims' experiences of the prosecution process and the decision to persist with it.

\section{Building resistance to compassion fatigue, secondary traumatic stress and burnout}

With the potential impact of compassion fatigue, secondary traumatic stress and burnout becoming increasingly well recognised, it has been suggested that increasing awareness of these issues is a matter of professional responsibility (Salston \& Figley, 2003). If it is the case that police officers' empathy is impeded by compassion fatigue, secondary traumatic stress or burnout, it will be particularly important to investigate what can be done to help maintain empathy, as well as to alleviate officer distress.

Organisational measures have been proposed to assist helping professionals, such as ensuring resources such as counselling, peer support groups or supervision are available 
(Figley, 1995), as well as debriefing and having regular opportunities to speak safely about the impact of the work (Mathieu, 2007). Other strategies focus more on the individual such as anxiety management and self-care (Gentry, 2002), and mindfulness (Thomas \& Otis, 2010; Thompson, Amatea \& Thompson, 2014). Some of these components have been included in resiliency programmes specifically designed to reduce compassion fatigue in professionals, such as the Accelerated Programme for Compassion Fatigue (Gentry \& Baranowsky, in press). There is some evidence in the healthcare field for the effectiveness of such interventions (Potter, Deshields, Berger, Clarke, Olsen \& Chen, 2013).

\section{Aims}

The first aim of the present study was to investigate levels of compassion fatigue, secondary traumatic stress and burnout in specialist police officers who work with victims of rape and sexual assault, and to examine whether levels of these variables were associated with length of service in this specialist role.

The second aim was to examine the relationship between empathy and compassion fatigue, secondary traumatic stress and burnout. Trait empathy was measured using questionnaires, and situation-specific empathy was measured using video vignettes designed to relate to specialist officers' work with adult victims of sexual assault.

The third aim was to pilot a brief training intervention aimed at increasing police officers' knowledge and awareness of compassion fatigue, secondary traumatic stress and burnout, as well as introducing them to self-help strategies concerning stress and anxiety management. Officers' knowledge of these different concepts was assessed before and after the intervention, with an 8 to 10 -week follow-up. Feedback about the training was also collected. 


\section{Method}

\section{Participants}

Police officers were recruited via the Training and Communications team of the Sexual Offences, Exploitation and Child Abuse (SOECA) Command of the London Metropolitan Police Service, from September 2014 to January 2015, with follow-up data being collected up until May 2015. Participants were invited to attend a 90-minute training session on compassion fatigue and stress-management at work.

The training was delivered either as part of officers' induction to the SOECA command, or as requested in various SOECA teams in different London boroughs. In total, the training was delivered in five different induction sessions from which 90 participants were recruited. In addition, requests for training were received from three 'satellite' teams, from which five further training sessions were delivered recruiting 52 participants who had more experience working in the SOECA command. Training was delivered by two of the authors in the role of Trainee Clinical Psychologists over a five-month period from September 2014 to January 2015. In each instance, training was delivered at various training venues of the London Metropolitan Police Service.

Overall, 142 participants took part in the training intervention across different boroughs of London. Sixty-two percent (88) of participants were female, with $38 \%$ (53) male. In terms of ethnicity, 89\% (124) were White British. Most participants worked with adult victims (66\%) as opposed to children (32\%). Years of experience working in the SOECA command ranged from 0-10 years $(M=1.7)$, whereas years of overall police experience varied from 3-30 years $(M=13.1)$. Those participants who had been working in SOECA for under a year were attending the training as part of their induction into the role. 
Ethical approval for the study was granted by the University College London Research Ethics Committee.

\section{Procedure}

Once participants had consented to take part in the research, they completed a set of questionnaires. Participants were then shown the three video vignettes (see below) and asked to complete a vignette questionnaire in order to measure situational empathy.

Of the 142 participants, 137 completed the measures immediately before and then after the training. The remaining five participants either opted not to complete measures altogether, or had to leave the training day early making them unable to complete follow-up measures. Hard copies of all measures were provided. Follow-up questionnaires were administered online 8-10 weeks after participants attended the training, with requests sent via email. Overall, 38 participants completed follow-up measures. The relatively low number of follow-up measures being completed could be explained by participants not having available time in which to complete the measures during working hours. For missing data, items were scored using the overall mean from the measure, using a mean score for the appropriate subscale where applicable.

\section{Video vignettes}

Three vignettes, designed for the present study, were shown to participants before and after the training. The vignettes depicted a woman describing the details of an acquaintance rape, looking straight at the viewer, as if they were describing it to an investigating officer. A range of presentation styles, characters and accounts were used, 
based on the 'mad, bad and real' victim profiles described in previous research (Maddox et al., 2012).

Scripts were based on accounts given on online rape support forums, with details altered in order to protect the identity of victims. Pilot scripts were then sent to an independent clinical psychologist experienced in working with rape and sexual assault cases in a PTSD service. He verified that the scripts were realistic and typical of the kind of case seen in the clinical practice.

Three female, white British actors were used to role-play the victims. Actors were similar in age and hair colour, and were filmed wearing plain black clothing, in the same room against a plain white background. They were given information about the study and about the supposed background of the victim's profile that they were portraying.

\section{Measures}

A single item empathy Likert scale was used in relation to the video vignettes.

Participants were asked to rate the level of empathy they felt towards the victim in the video using the question: "How much empathy do you feel towards this person?" Responses were measured using a Likert scale ranging from 1 (None) to 7 (A lot).

The Professional Quality of Life Scale (ProQOL; Stamm, 2010) is a 30-item self-report scale consisting of three subscales measuring compassion fatigue, compassion satisfaction and burnout. The measure asks participants to answer items in relation to the last 30 days. ProQOL items include "I find it difficult to separate my personal life from my life as a [helper]" (compassion fatigue), "I feel "bogged down" by the system" (burnout) and "I believe I can make a difference through my work" (compassion satisfaction). Responses are 
given on a scale from 1 (Never) to 5 (Very often). The measure was adapted slightly for the current population. For example, the original ProQOL item: "I am preoccupied with more than one person [I help]", was changed to: "I am preoccupied with more than one of the victims I have seen recently".

Mean ProQOL scores and standard deviations have been reported in previous studies in different populations (e.g. Carmel \& Friedlander, 2009; Connally, 2012; Eastwood \& Eckland, 2008; Flarity, Gentry \& Mesnikoff, 2013). Using the self-score methods described in the ProQOL manual, participants' scores on the compassion fatigue and burnout subscales were categorised as low, average or high. The ProQOL has been found to be reliable in previous research with alpha coefficients ranging from .85 to .94 (Figley \& Stamm, 1996; Stamm, 2002). For the purposes of the current study, only the compassion fatigue and burnout subscales were used in the analysis and each scale showed good reliability (compassion fatigue alpha $=.78$; burnout alpha $=.76$ ).

The Secondary Traumatic Stress Scale (STSS; Bride, Robinson, Yegidis, \& Figley, 2004) is a 17-item self-report scale designed to measure the emotional effects of indirect exposure to trauma in a professional context, including subscales for intrusion, avoidance and arousal symptoms. Participants are asked to provide responses relating to the past seven days on items such as "Reminders of my work with clients upsets me" (Intrusion subscale), "I wanted to avoid working with some clients" (Avoidance subscale), and "I had trouble concentrating" (Arousal subscale). Responses are given on a scale from 1 (Never) to 5 (Very often). Scores for each subscale can be derived, as well as an overall secondary traumatic stress score. Validation research has demonstrated good psychometric properties of the scale (Bride et al., 2004). 
Scores for the STSS can be categorised using procedures presented by Bride (2007). There are five categories overall, with scores below the $50^{\text {th }}$ percentile classified as little or no secondary traumatic stress, and further categories labelled as mild, moderate, high and severe secondary traumatic stress. Reliability was good for the STSS in the current population (alpha $=.91)$.

The Toronto Empathy Questionnaire (TEQ; Spreng, McKinnon, Mar, \& Levine, 2009) is a 16-item self-report scale designed to provide a unidimensional tool for measuring dispositional empathy. Items include "I remain unaffected when someone close to me is happy" and "I can tell when others are sad even when they do not say anything". Responses are given on a scale from 0 (Never) to 4 (Always). The TEQ has high internal reliability and convergent validity (Spreng et al., 2009). In the present study, the TEQ was modified by removing one item ("When I see someone being taken advantage of, I feel kind of protective towards him (her") which showed unusually large variance and atypical correlations with other items. The modified scale showed good reliability (alpha $=.79$ ).

A Pre and Post-Training Knowledge Measure was used to test the effectiveness of the training. The measure, which was designed for this study, asked for qualitative responses for definitions and signs of the key concepts, as well as what steps they could take to reduce or prevent them. Finally, participants were asked to rate how confident they felt in their responses using a Likert scale of 1 (no confidence) to 7 (complete confidence).

To score the knowledge measures, model answers for each item were devised by the researchers. These were based on the definitions provided in the training. For each answer, one point was given for each correct statement made, although not for synonyms or repetitions of the same answer. Initially, each researcher independently scored ten 
measures each, based on the model answers. Scores were then compared and any discrepancies identified and discussed. This led to modifications of model answers and identification of appropriate synonyms for correct responses. The entire data set was then scored based on the revised set of model answers.

Participants completed a demographics questionnaire that included items relating to their age, gender, ethnicity, job title, role and rank, years of service overall and in SOECA, and the borough in which they worked.

Following the training, participants completed a feedback questionnaire in which they commented on the training's usefulness and how it might be improved.

\section{Training content}

Training was divided into two parts. The first part included psychological education about stress, compassion fatigue, secondary traumatic stress and burnout. The second focused on self-help strategies that can be used to reduce or build resistance against compassion fatigue and stress more generally. The self-help section of the intervention was further broken down into six sections: 1 . Identifying physiological signs of stress; 2 . Selfcare; 3. Anxiety and stress management, e.g. relaxation strategies; 4. Social support and debriefing; 5. Mindfulness; and 6. Compassion satisfaction.

The content was based on literature for building resistance to compassion fatigue, secondary traumatic stress and burnout. A number of authors have advocated the use of self-care, identifying personal signs of stress and compassion fatigue, anxiety management strategies, social support, compassion satisfaction and mindfulness (Flarity, Gentry \& 
Mesnikoff, 2013; Gentry, 2002; Gentry \& Baranowsky, in press; Mathieu, 2012; Sexton, 1999; Thieleman \& Cacciatore, 2014).

This training was delivered alongside additional training on recognising possible signs of PTSD and shame in rape and sexual assault victims, which was devised and delivered for the purposes of a partner study (Glover, 2015).

\section{Power analysis}

For the cross-sectional part of the study, power analysis undertaken using "G*Power" (Faul, Erdfelder, Lang \& Buchner, 2007) software indicated that in order for a medium effect size of $r=0.3$ to be detected, a sample of 82 participants would be required, based on a correlation analysis, assuming an alpha of 0.05 (two-tailed) and power of 0.80 .).

For the pre and post-test design, a power analysis using the same software indicated that in order for a medium effect size of $d=0.5$ to be detected, a sample of 34 participants would be required, assuming an alpha of 0.05 (two-tailed) and power of 0.80 . Statistical analyses were carried out using IBM/SPSS Statistics v. 21.

\section{Results}

\section{What levels of compassion fatigue, secondary traumatic stress and burnout were} reported?

Contrary to expectations, there was little evidence of elevated compassion fatigue, secondary traumatic stress or burnout in the sample. For compassion fatigue $(M=18.4, S D=$ 4.7), around $84 \%$ of participants' scores ranked as being low, with $16 \%$ being average and none as high. For burnout $(M=25.3, S D=6.1)$, around $33 \%$ of participants' scores ranked as low, with $67 \%$ falling in the average category, and none ranked as high. 
For secondary traumatic stress $(M=32.5, S D=10.6), 74 \%$ of participants fell into the bottom two categories, indicating little, no or mild secondary traumatic stress. Around $26 \%$ fell into the moderate, high and severe categories ( $11 \%$ moderate, $8 \%$ high, $8 \%$ severe). In terms of subscales, mean scores for intrusions and avoidance fell just above the $50^{\text {th }}$ percentile, suggesting low levels of these constructs. Scores for arousal were higher, around the $75^{\text {th }}$ percentile, suggesting mild levels. Compassion fatigue, secondary traumatic stress and burnout were all positively correlated with each other, with correlations ranging from .56 to .66 (all $p<.001$ ), but not strongly enough to warrant combining them into a single index.

\section{Are compassion fatigue secondary traumatic stress and burnout related to years of experience and demographic variables?}

Participants who had spent longer working in SOECA had higher compassion fatigue, secondary traumatic stress and burnout scores. Importantly, these results were not replicated when comparing these variables with years of overall experience, suggesting that something specifically related to working with rape victims increases compassion fatigue, secondary traumatic stress and burnout over time (see Table 1).

There were no significant relationships found between compassion fatigue, secondary traumatic stress and burnout, and the demographic variables of age, sex and ethnicity.

Participants who had been in the role for a year or more $(M=37.0, S D=11.7, N=67)$ had higher secondary traumatic stress scores than those in role for less than a year $(M=$ 
29.8, $S D=9.0, N=40 ; t(104)=3.6, p=0.001)$. However, compassion fatigue did not differ between these two groups.

Participants working with adults $(M=34.3, S D=10.7, \mathrm{~N}=72)$ experienced higher levels of secondary traumatic stress than those working with children $(M=27.4, S D=8.5, N$ $=34 ; t(104)=3.3, p=0.001)$. Participants working with adults also experienced higher levels of burnout $(M=26.7, S D=6.0)$ than those working with children $(M=22.2, S D=4.8 ; t(105)$ $=3.8, p=0.0002)$. Differences in compassion fatigue scores were not significant.

\section{Empathy, compassion fatigue, secondary traumatic stress and burnout}

There were no significant associations found between either compassion fatigue or secondary traumatic stress and empathy as measured by the TEQ or the vignettes (see Table 2). However, lower burnout was related to higher dispositional empathy as measured by the TEQ.

Because a large subgroup of participants had not worked in the SOECA command for very long, it is possible that their relative lack of exposure to victims influenced the relationships between empathy, compassion fatigue and secondary traumatic stress. Therefore, further correlation analyses were conducted to determine whether associations between empathy, compassion fatigue and secondary traumatic stress applied for a subgroup of participants who had worked in SOECA for at least 12 months $(\mathrm{N}=40)$. The same analyses as above were conducted and similar non-significant patterns were found.

Did the training intervention increase participants' knowledge of compassion fatigue, secondary traumatic stress and burnout? 
Knowledge scores increased from pre-training to post-training $(\mathrm{t}(121)=4.5, \mathrm{p}<.001$, $d=.44 ;$ see Table 3 ). A repeated measures ANOVA showed that there were also differences in knowledge scores between pre-training, post-training and follow-up $(F(1,32)=11.9, p=$ .002). Post-hoc analyses suggest that knowledge increase had been maintained at follow-up, albeit from the small sub-sample of participants who completed the follow-up measures.

\section{Training feedback}

When giving feedback, $86 \%$ of participants rated the item: "I know more about compassion fatigue and how that may impact on my work" as either 6 or 7 (Strongly agree). Many participants commented on the benefits of recognising and understanding compassion fatigue and being able to 'give a name' to what they were experiencing:

"Learning to recognise and be allowed to have these feelings and emotions", "Glad to learn about compassion fatigue and realise I'm not weird".

Some participants commented that they would appreciate further support from their employers at an organisational level to help them cope: "I would passionately like to see proper recognition for the work we do and be able to offer regular counselling to all our staff...how can we do without?" Managerial staff present during the training also expressed how they would benefit from being more confident in identifying signs of compassion fatigue, secondary traumatic stress and burnout in their staff so that they could take steps at a managerial level to help.

As part of the follow-up questionnaires, participants were asked to describe which, if any, of the self-help measures described in the training they had since put into practice. In total, 17 participants responded to this item. The most commonly reported self-help 
strategy was mindfulness, with nine participants saying that they had embarked on regular mindfulness practices and made use of mindfulness smartphone applications.

\section{Discussion}

Although overall levels of compassion fatigue, secondary traumatic stress and burnout were within the normal range, greater levels of these variables were all related to having more experience working with victims of rape and sexual assault, but not to overall years of police service. This suggests that something specific about working in this role compared with police work more generally, makes officers more prone to compassion fatigue, secondary traumatic stress and burnout. This finding is supported by the idea that exposure to traumatic material is required for these problems to develop (Bride, 2007; Figley, 1995).

The fact that compassion fatigue, secondary traumatic stress and burnout increase over time could be explained using a cumulative stress model, in that greater exposure over time to the trauma of others increases the risk of distress (Figley, 1995; Flannelly, Roberts \& Weaver, 2005). However, some studies have failed to replicate these findings (e.g. Boscarino, Figley \& Adams, 2004; Thompson, Amatea \& Thompson, 2014).

The hypothesis that officers with higher amounts of dispositional empathy would be more likely to experience compassion fatigue and secondary traumatic stress was not supported. This finding challenges the model of compassion fatigue which proposes that highly empathic individuals are more likely to develop compassion fatigue and secondary traumatic stress. 
The fact that no associations were found between situational empathy and compassion fatigue and secondary traumatic stress suggests that officers' empathy towards victims was not being affected. It may be that officers were not experiencing levels of compassion fatigue and secondary traumatic high enough to affect their empathy. The amount of compassion fatigue and secondary stress required to affect empathy levels however is not discussed in the literature.

Because Figley's model was created in a psychotherapy context, it may be that there are inherent differences between psychotherapy and police interview work that explains these findings. However, the fact that compassion fatigue, secondary traumatic stress and burnout have been found to be evident in non-therapist populations has demonstrated that it can develop in a range of helping professions. It is reasonable therefore to extend this to police officers, with the results from the present study suggesting that some officers do experience these difficulties.

The fact that burnout was inversely related to dispositional empathy suggests that empathy reduces as burnout increases and vice versa; a finding that has been replicated in medical students (Brazeau, Schroeder, Rovi, \& Boyd, 2010; Thomas, Dyrbye, \& Huntington, 2007). These studies rated how much empathy participants had felt recently towards their patients, rather than their dispositional empathy. It is possible that having higher dispositional empathy makes officers less likely to develop burnout. It has been suggested that empathy can serve to protect helping professionals against stress and burnout by making professional practice more meaningful (Halpern, 2003; Roter, Stewart, Putnam \& Lipkin, 1997). 
Most officers rated that they learned a lot from the training, which was reflected in the knowledge measure scores. These findings suggest that a training intervention of this nature is useful. However, more work is required to determine whether an increase in knowledge leads to uptake of self-help strategies and in turn that these are effective.

\section{Limitations}

A major limitation of the study is that the cross-sectional design was not sufficient to shed light on the causal direction of the relationships between empathy, compassion fatigue, secondary traumatic stress and burnout. A longitudinal design would enable hypotheses about whether, for example, high empathy was a risk factor for compassion fatigue, to be tested. The present study attempted to overcome this problem by measuring both dispositional and situational empathy, on the assumption that the former would provide a stable measure of empathy and the latter as a measure of how much empathy was actually felt towards victims. Nevertheless, a longitudinal design would be preferable, in order to test whether empathy, or indeed compassion fatigue, secondary traumatic stress and burnout change over time.

A number of assumptions were made about the way in which empathy was measured that may have affected the validity of the findings. For example, it was assumed that the TEQ would be a sufficient measure of dispositional empathy, rather than a measure of empathy felt towards victims specifically. While the measure does not ask participants to reflect on their recent experiences or feelings towards victims, it may be that it was interpreted in this way. It was also assumed that this measure of empathy reflected how empathic a person is generally and as such is not something that would change in different situations. 
In order to more fully assess the effects of compassion fatigue, secondary traumatic stress and burnout, it would have been preferable to use a sample of officers who had been in role for a substantial length of time. However, because of difficulties in recruiting participants and time constraints, many participants had only joined the SOECA command quite recently, so they may have had little contact with victims.

\section{Implications}

Given that compassion fatigue, secondary traumatic stress and burnout all appeared to increase over time, it is important for police service to raise awareness of these issues. Anecdotal evidence from officers suggested that they would benefit from extra support in their challenging work with victims, often in the context of additional pressures of working within the criminal justice system. While the use of self-help strategies has the potential to be of benefit, this should not replace organisational support such as supervision and peer support groups in order to help officers to stay and be effective in this role for longer.

Greater recognition of the potential psychological challenges of working in this area could also serve to normalise these reactions and give officers confidence to speak about the challenges they face. Officers could also be encouraged, for example through refresher training, to practise self-help strategies, and to maintain their awareness of the potential for compassion fatigue, secondary traumatic stress and burnout to develop over time.

There was a proportion of officers who were experiencing average levels of burnout and average to high levels of secondary traumatic stress. Given the apparent effects of time spent working with victims in this sample, it is reasonable to assume that there are risks associated with this work that render officers vulnerable to developing psychological 
difficulties. While the links between these effects and empathy remain unclear, the psychological well-being of these officers is important not only for their professional quality of life but for the quality of service they provide for victims of rape.

\section{Future research}

Many interesting questions have been raised from this study that give scope for future research. The factors that make rape victims more or less likely to opt to stay in the prosecution process go well beyond their interactions with investigating police officers. Nevertheless, it is important to investigate ways in which the police can help victims feel supported. Helping police officers themselves to maintain their own psychological wellbeing remains a useful avenue for indirectly helping victims and of ensuring the rate of convictions for rape continues to increase. The findings here suggest that training can increase knowledge of key concepts, but further research could investigate whether training interventions can reduce compassion fatigue, secondary traumatic stress and burnout over time.

Longitudinal methods would allow investigation of whether officers with higher dispositional empathy do indeed go on to develop compassion fatigue and secondary traumatic stress, as well as whether empathy felt towards victims reduces over time as a result. In addition, further support for the present study's finding regarding burnout and empathy could be corroborated in a longitudinal design.

A broader challenge for research in this area is to develop clearer distinctions between key variables, particularly between compassion fatigue and burnout. As constructs, they both purport to describe psychological and physical effects of mentally and emotionally 
demanding work that develop over time. Conclusive findings in research of this type might be hindered by conceptual overlap between the two constructs, which could essentially be tapping into a shared characteristic, such as emotional exhaustion.

Figley's model has been criticised for not being explicit in terms of what types of empathy are involved in the development of compassion fatigue (Sabo, 2011), so it would be useful to measure empathy in different ways. In particular, an empathy measure that captures how much empathy is actually displayed by officers towards victims, such as The Therapist Empathy Scale (Decker, Nich, Carroll \& Martino, 2014), would be more externally valid. Past research has suggested that victims' perceptions of police officers does influence their willingness to disclose information and remain in the prosecution process (Greeson et al., 2015; Maddox et al., 2011). Longitudinal studies aiming to test Figley's model would be extremely useful to further understanding in this field.

The findings provide tentative support for the idea that empathically engaging with victims might serve as a protective factor against burnout. It would be interesting to explore this further, firstly to verify this finding, and secondly to examine the mechanisms by which empathy might reduce burnout. Qualitative research could explore further the idea that empathic engagement can make helping professionals' work feel more meaningful. Some studies have found that professionals with higher levels of compassion satisfaction have lower compassion fatigue, secondary traumatic stress and burnout (e.g. Collins \& Long, 2003; Simon, Pryce, Roff \& Klemmack, 2006; Thomas \& Otis, 2010), and further research could explore what role empathy might play in these relationships.

Because compassion fatigue, secondary traumatic stress and burnout increase with experience in this sample, it is important to investigate what can be done to help officers 
build resistance to these effects. The present study found that officers valued training on these subjects and future research could investigate the usefulness of other interventions, e.g. mindfulness, using experimental designs.

\section{References}

Bohart, A.C., \& Greenberg, L.S. (1997). Empathy: Where are we and where do we go from here? In A.C. Bohart \& L.S. Greenberg (Eds.). Empathy reconsidered: New directions in psychotherapy (pp. 419-450). Washington, DC: American Psychological Association.

Boscarino, J.A., Figley, C.R., \& Adams, R.E. (2004). Compassion fatigue following the September 11 terrorist attacks: A study of secondary trauma among New York City social workers. International Journal of Emergency Mental Health, 6, 57-66.

Brazeau, C.M.L.R., Schroeder, R., Rovi, S., \& Boyd, L. (2010). Relationships between medical student burnout, empathy, and professionalism climate. Complexities in Behavior and Assessment, 85(10), 33-36.

Bride, B.E. Robinson, M.M., Yegidis, B., \& Figley, C.R. (2004). Development and validation of the Secondary Traumatic Stress Scale. Research on Social Work Practice, 14(1), 2735. 
Bride, B.E. (2007). Prevalence of secondary traumatic stress among social workers. Social Work, 52(1), 63-70.

Carmel, M.J.S., \& Friedlander, M.L. (2009). The relation of secondary traumatization to therapists' perceptions of the working alliance with clients who commit sexual abuse. Journal of Counseling Psychology, 56(3), 461-467.

Casciani, D. (2014, June 6). Measures aimed at addressing drop in rape convictions launched. BBC News. Retrieved from http://www.bbc.co.uk/news/uk.

Channel 4 News. (2014, June 6). Why are rape conviction rates falling? Retrieved from http://www.channel4.com/news.

Cicognani, E., Pietrantoni, L., Palestini, L., \& Prati, G. (2009). Emergency workers' quality of life: The protective role of sense of community, efficacy beliefs and coping strategies. Social Indicators Research, 94(3) 449-463.

Collins, S. \&. Long, L. A. (2003). Too tired to care? The psychological effects of working with trauma. Journal of Psychiatric and Mental Health Nursing, 10, 17-27.

Connally, D. (2012). The relationship between clinician sex, ethnicity, sexual identity and secondary traumatic stress. Journal of Gay \& Lesbian Mental Health, 16, 306-321.

Crown Prosecution Service. (2014). Violence against women and girls crime report 20132014. Retrieved from http://www.cps.gov.uk/publications/equality/vaw/.

Decker, S.E., Nich, C., Carroll, K.M., \& Martino, S. (2013). Development of the therapist empathy scale. Behavioural and Cognitive Psychotherapy, 42, 339-354. 
Eastwood, C.D., \& Ecklund, K. (2008). Compassion fatigue risk and self-care practices among residential treatment center childcare workers. Residential Treatment for Children \& Youth, 25(2), 103-122.

Elwood, L.S., Mott, J., Lohr, J.M., \& Galovski, T.E. (2011). Secondary trauma symptoms in clinicians: A critical review of the construct, specificity, and implications for traumafocused treatment. Clinical Psychology Review, 31(1), 25-36.

Evces, M.R. (2015). What is vicarious trauma? In G. Quitangon \& M.R. Evces (Eds.), Vicarious trauma and disaster mental health (pp. 9-23). New York: Routledge.

Faul, F., Erdfelder, E., Lang, A.G., \& Buchner A. (2007). G*Power 3: A flexible statistical power analysis program for the social, behavioral, and biomedical sciences. Behavioural Research Methods, 39(2), 175-191.

Figley, C.R. (1995). Compassion fatigue as secondary traumatic stress disorder: An overview. In C.R. Figley (Ed.). Compassion fatigue: Coping with secondary traumatic stress disorder in those who treat the traumatized (p. 1-20). New York: Brunner-Routledge.

Figley, C.R., \& Stamm, B.H. (1996). Psychometric review of Compassion Fatigue Self Test. In B.H. Stamm (Ed.), Measurement of stress, trauma, and adaptation (pp. 127-130). Maryland: Sidran Press.

Figley, C.R. (2002). Compassion fatigue: Psychotherapists' chronic lack of self-care. Journal of Clinical Psychology, 58(11), 1433-1441. 
Flannelly, K.J., Roberts, R.S.B., \& Weaver, A.J. (2005). Correlates of compassion fatigue and burnout in chaplains and other clergy who responded to the September 11th attacks in New York City. The Journal of Pastoral Care \& Counseling, 59(3), 213-224.

Flarity, K., Gentry, E.J., \& Mesnikoff, N. (2013). The effectiveness of an educational program on preventing and treating compassion fatigue in emergency nurses. Advanced Emergency Nursing Journal, 35(3), 247-258.

Gentry, E.J. (2002). Compassion fatigue: A crucible of transformation. Journal of Trauma Practice, 1(3-4), 37-61.

Gentry, E.J., \& Baranowsky, A.B. (in press). Compassion fatigue resiliency - a new attitude. Compassion fatigue - programs with legs: The ARP, CFST, \& CF resiliency training.

Gleichgerrcht, E., \& Decety, J. (2014). The relationship between different facets of empathy, pain perception and compassion fatigue among physicians. Frontiers in Behavioral Neuroscience, 8, 243.

Glover, N.K.E. (2015). The impact of training police officers in identifying PTSD and shamebased behaviours in victims of sexual assault. Unpublished clinical psychology doctoral thesis, Department of Clinical, Educational, and Health Psychology, University College London.

Greeson, M.R., Campbell, R., \& Fehler-Cabral, G. (2015). Cold or caring? Adolescent sexual assault victims' perceptions of their interactions with the police. Violence and Victims, 29(4), 636-651. 
Halpern, J. (2003). What is clinical empathy? Journal of General Internal Medicine, 18, 670674.

Hegney, D.G., Craigie, M., Hemsworth, D., Osseiran-Moisson, R., Aoun, S., Francis, K., \& Drury, V. (2014). Compassion satisfaction, compassion fatigue, anxiety, depression and stress in registered nurses in Australia: Study 1 results. Journal of Nursing Management, 22, 506-518.

Kilpatrick, D.G., Saunders, B.E., Veronen, L.J., Best, C.L., \& Von, J.M. (1987). Criminal victimization: Lifetime prevalence, reporting to police, and psychological impact. Crime \& Delinquency, 33(4), 479-489.

La Bash, H., \& Papa, A. (2014). Shame and PTSD symptoms. Psychological Trauma: Theory, Research, Practice, and Policy, 6(2), 159.

Lee, D.A., Scragg, P., \& Turner, S.W. (2001). The role of shame and guilt in traumatic events: A clinical model of shame-based and guilt-based PTSD. British Journal of Medical Psychology, 74, 451-466.

López-Pérez, B., Ambrona, T., Gregory, J., Stocks, E., \& Oceja, L. (2013). Feeling at hospitals: Perspective-taking, empathy and personal distress among professional nurses and nursing students. Nurse Education Today, 33(4), 334-338.

Maddox, L., Lee, D.A., \& Barker, C. (2011). Police empathy and victim PTSD as potential factors in rape case attrition. Journal of Police and Criminal Psychology, 26, 112-117. 
Maddox, L., Lee, D.A., \& Barker, C. (2012). The impact of psychological consequences of rape on rape case attrition: The police perspective. Journal of Police and Criminal Psychology, 27, 33-44.

Maslach, C. (1982). Burnout: The Cost of Caring. Englewood Cliffs, NJ: Prentice Hall.

Maslach, C., Schaufeli, W.B., \& Leiter, M.P. (2001). Job burnout. Annual Review of Psychology, 52(1), 397-422.

Mathieu, F. (2007). Running on empty: Compassion fatigue in health professionals. Retrieved from http://www.compassionfatigue.org/pages/RunningOnEmpty.pdf.

Mathieu, F. (2012). The Compassion Fatigue Workbook: Creative Tools for Transforming Compassion Fatigue and Vicarious Traumatization. New York: Routledge.

May, W. (2013). Maintaining empathy in medical education. Medical Teacher, 35(12), 977978.

Patterson, D. (2011). The impact of detectives' manner of questioning on rape victims' disclosure. Violence Against Women, 17(11), 1349-1373.

Pegram, S.E., \& Abbey, A. (2016). Associations between sexual assault severity and psychological and physical health outcomes: Similarities and differences among African American and Caucasian survivors. Journal of Interpersonal Violence, published online before print.

Potter, P., Deshields, T., Berger, J.A., Clarke, M., Olsen, S., \& Chen, L. (2013). Evaluation of a compassion fatigue resiliency program for oncology nurses. Oncology Nursing Forum, 40(2), 180-187. 
Rogers, C. (1975). Empathic: An unappreciated way of being. The Counseling Psychologist, 5(2), 2-10.

Roter, D., Stewart, S., Putnam, N., Lipkin, M. (1997). Communication patterns of primary care physicians. The Journal of the American Medical Association, 277, 350-356.

Sabo, B. (2011). Reflecting on the concept of compassion fatigue. The Online Journal of Issues in Nursing, 16(1).

Salston, M., \& Figley, C.R. (2003). Secondary traumatic stress effects of working with survivors of criminal victimization. Journal of Traumatic Stress, 16, 167-174.

Schauben, L.J., \& Frasier, P.A. (1995). Vicarious trauma: The effects on female counsellors of working with sexual violence victims. Psychology of Women Quarterly, 19, 49-64.

Sexton, L. (1999). Vicarious traumatisation of counsellors and effects on their workplaces. British Journal of Guidance \& Counselling, 27(3), 393-403.

Simon, C.E., Pryce, J.G., Roff, L.L., \& Klemmack, D. (2005). Secondary traumatic stress and oncology social work: Protecting compassion from fatigue and compromising the worker's worldview. Journal of Psychosocial Oncology, 23(4), 1-14.

Spreng, N.R., McKinnon, M.C., Mar, R.A., \& Levine, L. (2009). The Toronto Empathy Questionnaire: Scale development and initial validation of a factor-analytic solution to multiple empathy measures. Journal of Personality Assessment, 91(1), 62-71.

Stamm, B.H. (2010). The ProQOL (Professional Quality of Life Scale: Compassion satisfaction and compassion fatigue). Pocatello, ID: ProQOL.org. Retrieved from www.proqol.org. 
Thieleman, K. \& Cacciatore, J. (2014). Witness to suffering: Mindfulness and compassion fatigue among traumatic bereavement volunteers and professionals. Social Work, 59.

Thomas, J.T. \& Otis, M.D. (2010). Intrapsychic correlates of professional quality of life: Mindfulness, empathy, and emotional separation. Journal of the Society for Social Work and Research, 1, 83-98.

Thomas, M.R., Dyrbye, L.N., Huntington, J.L., Lawson, K.L., Novotny, P.J., Sloan, J.A., Shanafelt, T.D. (2007). How do distress and well-being relate to medical student empathy? A multicenter study. Journal of General Internal Medicine, 22(2), 177-183.

Thompson, I.A., Amatea, E.S., \& Thompson, E.S. (2014). Personal and contextual Predictors of mental health counselors' compassion fatigue and burnout. Journal of Mental Health Counseling, 36, 58-77.

Yan, G.W., \& Beder, J. (2013). Professional quality of life and associated factors among VHA chaplains. Military Medicine, 178(6), 638-645.

Zeidner, M., Hadar, D., Matthews, G., \& Roberts, R. D. (2013). Personal factors related to compassion fatigue in health professionals. Anxiety, Stress, \& Coping: An International Journal, 26, 595-609. 
Table 1. Spearman's Rho correlation statistics between years of experience in SOECA, overall years of service, compassion fatigue, secondary traumatic stress and burnout

\begin{tabular}{cccc}
\hline & Compassion fatigue & $\begin{array}{c}\text { Secondary traumatic } \\
\text { stress }\end{array}$ & Burnout \\
\hline $\begin{array}{c}\text { Time spent working in } \\
\text { SOECA }\end{array}$ & $.26^{* *}$ & $.40^{* * *}$ & $.39^{* * *}$ \\
$\begin{array}{c}\text { Years overall service } \\
\text { yen }\end{array}$ & .02 & -.010 & .02 \\
\hline
\end{tabular}

${ }^{*} p<.05 * * p<.01 * * * p<.001$ 
Table 2. Correlations between empathy and compassion fatigue, secondary traumatic stress and burnout

Compassion fatigue

Secondary traumatic stress

\begin{tabular}{lccc}
\hline Trait empathy (TEQ) & .01 & -.02 & $-.31^{* * *}$ \\
Situational empathy & -.17 & -.09 & -.25 \\
(vignette) & & & \\
\hline
\end{tabular}

${ }^{*} p<.05 * * p<.01 * * * p<.001$ 
Empathy and compassion fatigue in police officers

Table 3. Knowledge measure mean scores

\begin{tabular}{cccc}
\hline Time point & M & SD & N \\
\hline Pre-training & 4.24 & 2.00 & 135 \\
Post-training & 5.20 & 2.29 & 127 \\
Follow-up & 5.54 & 2.01 & 37 \\
\hline
\end{tabular}

